\title{
Driving Direction Displacement Analysis of Asphalt Pavement under Fluctuating Load
}

\author{
Gao Jianhong ${ }^{1, *}$, Xu Youjun ${ }^{1}$, and Yang Shengchun ${ }^{1}$ \\ ${ }^{1}$ Civil Engineering School, UST Inner Mongolia, Inner Mongolia, Baotou 014010, China
}

\begin{abstract}
The finite element software ANSYS is used to build the asphalt pavement three-dimensional model and to carry through transient analysis. The z-direction displacement time history curves of asphalt pavement under half wave sine load are obtained. The curves reveal that the dynamic load influence on pavement structure Z-direction displacement is complex; The Z-direction displacement always reaches its peak value when the load reaches this point, and it decreases rapidly to zero after the load leaves; The Zdirection displacement influence of dynamic load increases with the increase of depth. These conclusions can provide a reference for asphalt pavement under half wave sinusoidal dynamic load.
\end{abstract}

\section{Introduction}

Compared with other static loads structures, the loads on pavement structures are mobile ${ }^{[1-2]}$. The load on the road is constantly changing because of the road surface unevenness and the vehicle itself vibration characteristics. At present, many scholars have carried out research on pavement structure dynamic response under dynamic load. For example, Zou Jingrong et ${ }^{[3]}$ studied the trunk road asphalt pavement failure mechanism by using BISAR software to establish a three-dimensional model. Wei Lianyu et ${ }^{[4]}$ simulated the driving dynamic load change caused by uneven pavement through using ABAQUS to establish a threedimensional finite element model. Zhou Zhengfeng et ${ }^{[5]}$ analyzed the mechanical response laws of pavement structure and subgrade under different axle types and axle loads through several typical asphalt pavement structure combinations. Chen Huaxin et ${ }^{[6]}$ analyzed the impact of overload, braking and other horizontal loads on asphalt pavement by using finite element software ABAQUS to establish a three-dimensional model. Wu Jinting and others ${ }^{[7]}$ considered the different effects of dynamic load and temperature on asphalt pavement structure. Each of the above-mentioned authors has its own research emphasis. Based on vibration theory and structural dynamics, an asphalt pavement threedimensional finite element model $^{[8]}$ is established by using ANSYS/APDL software in this paper. The pavement structure z-direction displacement time history curves under the fluctuating load are analyzed in order to provide references for asphalt pavement under different dynamic loads.

\section{Calculating parameters}

\subsection{Pavement structure combination}

The modulus of elasticity, thickness, Poisson's ratio and density of surface and base in asphalt pavement structure combination are shown in Table 1 . The pavement structure damping adopts Rayleigh damping. Referring to relevant references ${ }^{[8]}$, the pavement structure damping ratio is $\zeta=5 \%$, and $\alpha=2.6907$, $\beta=0.0009$.

Assuming: the pavement structural layers are continuous homogeneous and isotropic linear elastic materials; All pavement structural layers are completely continuous in vertical direction; Under the traffic load, there will be no emptying between the layers; There is a complete continuous contact condition between asphalt surface and base.

Table 1. Pavement and material parameters

\begin{tabular}{|c|c|c|c|c|}
\hline $\begin{array}{c}\text { Structural } \\
\text { layer }\end{array}$ & $\begin{array}{c}\text { Modulus } \\
/ \mathbf{M P a}\end{array}$ & $\begin{array}{c}\text { Thicknes } \\
\mathbf{s} / \mathbf{c m}\end{array}$ & $\begin{array}{c}\text { Poisso } \\
\mathbf{n} \text { ratio }\end{array}$ & $\begin{array}{c}\text { Density } \\
/ \mathbf{~ k g} / \mathbf{m}^{\mathbf{3}}\end{array}$ \\
\hline $\begin{array}{c}\text { asphalt } \\
\text { surface }\end{array}$ & 9000 & 20 & 0.25 & 2400 \\
\hline $\begin{array}{c}\text { granular } \\
\text { base }\end{array}$ & 300 & 40 & 0.35 & 2200 \\
\hline subgrade & 80 & - & 0.40 & 1800 \\
\hline
\end{tabular}

\subsection{Finite Element Model Establishment}

This paper chooses multi-layer pavement structure combination and applies elastic layer system theory to analyze. The calculation model is shown in Figure 1. The pavement three-dimensional model dimension $(\mathrm{X}, \mathrm{Z}$,

\footnotetext{
* Corresponding author: gjh76219@163.com
} 
Y) is $6.0 \mathrm{~m} \times 10.0 \mathrm{~m} \times 0.6 \mathrm{~m}$. Four kinds of elements are used in the model: spring element for simulating soil foundation COMBIN14, and surface effect units SURF154, and plane elements for building twodimensional solid structural model PLANE42, and equal parameter elements constituting three-dimensional solid structures SOLID45. Spring elements consider its axial performance only and its axial spring constant is $8 \times 10^{7} \mathrm{~N} / \mathrm{m}$ and damping coefficient is $1 \times 10^{5} \mathrm{~N} \cdot \mathrm{S} / \mathrm{m}$.

The boundary conditions: the driving $\mathrm{Z}$ direction is $\mathrm{UZ}=0$; the width $\mathrm{X}$ direction is $\mathrm{UX}=0$; the spring bottom is constrained completely. In engineering design, wheel load is simplified as equivalent circular uniform load, but considering that the imprint between tire and pavement is not circular, but closer to rectangle; so the loading area in this paper is calculated according to rectangle. The standard axle load is $100 \mathrm{kN}$ and the tire pressure is $0.7 \mathrm{MPa}$. Considering the mesh size in the driving area, the rectangle length and width are as follows: width $\times$ length $=0.20 \mathrm{~m} \times 0.28 \mathrm{~m}$.

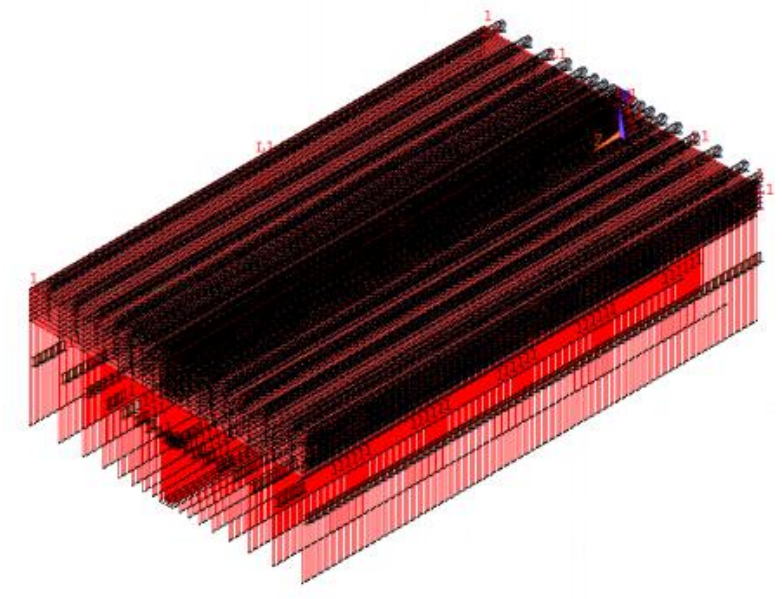

Fig. 1. Three-dimensional finite element model

\subsection{The half-wave sinusoidal load application}

The transient analysis in this paper adopts the FULL method. In order to save calculation time and obtain enough accuracy, the load strip range mesh is denser. And the farther from the load range, the sparser the mesh is.

By using software programming language APDL, the load is moved from the starting position to the prescribed position at the same speed by compiling do and enddo cyclic statements. After each load step is solved, the load is deleted, and then applied to the next contact surface to continue solving, and then forward to end. As shown in Figure 2, the half-wave sinusoidal load with uniform moving speed is used to simulate it with the following formula:

$$
\begin{gathered}
P(t)=\left|P_{m} \times \sin \left(\frac{\pi}{T} t\right)\right| \\
T=\frac{12 \delta}{V}
\end{gathered}
$$

In the formula: $P(t)$ for the distribution of load with time, $t$ is time; $P_{m}$ is $10_{\mathrm{a}} \mathrm{d}$ amplitude, taking the static pre ${ }_{\mathrm{S}}$ sure of standard axle load 0.7MPa;T is load cycle, $\mathrm{s} ; V$ is vehicle speed, $\mathrm{m} / \mathrm{s} ; \delta$ is tire grounding area equivalent circle radius, $0.1065 \mathrm{~m}$.

In this paper, the designed speed is $V=12.5 \mathrm{~m} / \mathrm{s}=45 \mathrm{~km} / \mathrm{h}$. According to the above formula, as $V=12.5 \mathrm{~m} / \mathrm{s}$, the period $T=0.10224 \mathrm{~s}$.

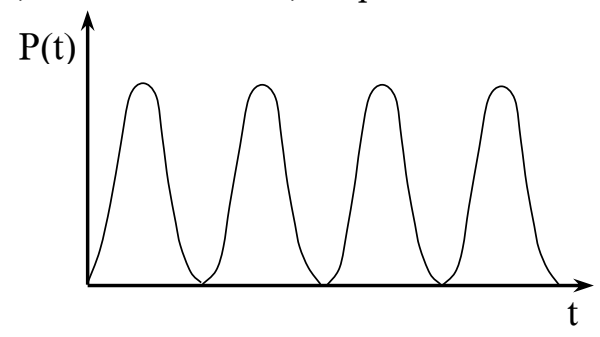

Fig. 2. Half wave sinusoidal load

\section{Numerical simulation results analysis}

As shown in Figure 3, the load moves in the $\mathrm{Z}$ positive direction. In order to clearly show the road structure different positions mechanical response under the halfwave sinusoidal load, four nodes are selected. The surface layer is point 1 . The bottom of the surface layer is point 2.The middle of the base course is point 3, and the bottom of the base course is point 4.This paper mainly studies the 4 points z-direction displacement time history curve.

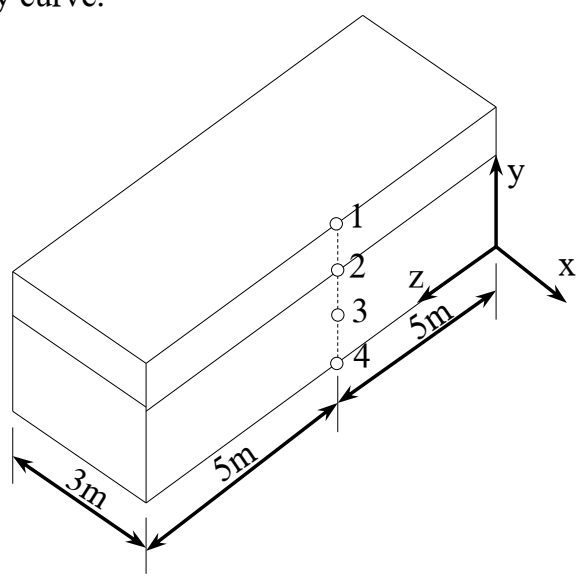

Fig.3. Sectional view along YZ plane

\subsection{Z-direction displacement time history curve analysis of point 1 and point 2}

Fig. 4 is the z-direction displacement time history curve of point 1 in the direction of half wave sinusoidal load movement. Table 2 shows the maximum, minimum and corresponding time of Z-direction displacement of 4 points. It can be seen from the Figure 4 and table 2 that when the vehicle starts to move from the starting position, point 1 , which is 5 meters away from it, almost starts to show small fluctuations at the same time.As the vehicle approaches, the point 1z-direction displacement 
decreases rapidly. When the time is about 0.340 seconds, the minimum value is $-1.166 \times 10-5 \mathrm{~m}$. Then, with the shock and approach of the load, the z-direction displacement increases rapidly to the maximum. When the time is about 0.376 seconds, it increases to the maximum value of $1.231 \times 10-5 \mathrm{~m}$. Then it rapidly reduces to the zero point, and presents a small fluctuation state with the vehicle load moving forward.

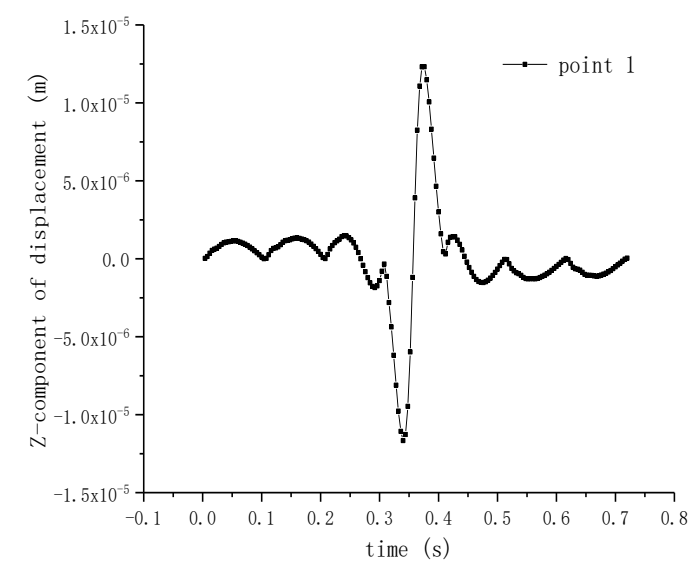

Fig.4. Point 1 time history curve.

Fig. 5 is the z-direction displacement time history curve of point 2 in the direction of half wave sinusoidal load movement. Combined with table 2 analysis curve: similar to point 1 , when the vehicle starts to move from the starting position, point 2 , which is 5 meters away from it, starts to show small fluctuations at the same time. With the vehicle approaching, the point $2 \mathrm{z}$-direction displacement increases rapidly. When the time is 0.340 seconds, the maximum value is $1.276 \times 10-5 \mathrm{~m}$. Then, with the shock and approach of the load, the z-direction displacement is rapidly reduced to the minimum. When the time is 0.376 seconds, it is reduced to the minimum value of $-1.353 \times 10-5 \mathrm{~m}$. Then it quickly rises to the zero and presents a small fluctuation state with the vehicle load moving forward.

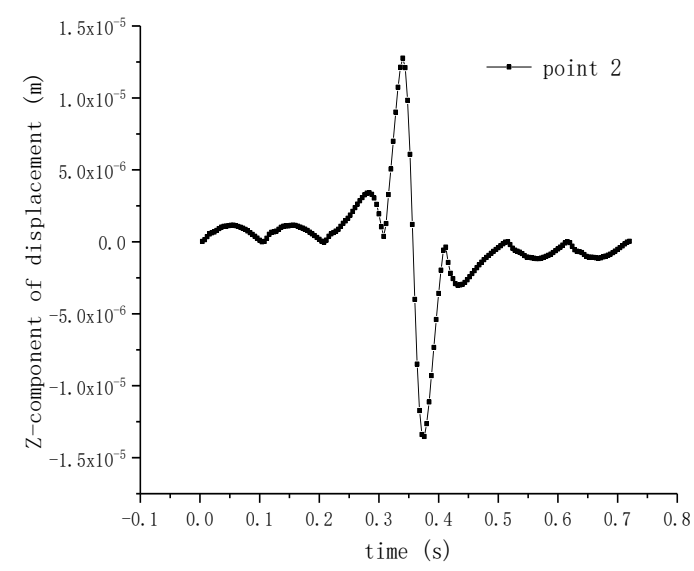

Fig.5. Point 2 time history curve
Compared with Fig. 4 and Fig. 5, at 0.340 seconds, the displacement of point 1 decreases to the minimum, while that of point 2 increases to the maximum. Then, at 0.376 seconds, the displacement of point 1 increases to the maximum and that of point 2 decreases to the minimum. It shows that the fluctuating load has great different influence on point 1 and point 2 .

\subsection{Z-direction displacement time history curve analysis of point 3 and point 4}

Fig. 6 is the z-direction displacement time history curve of point 3 and 4 in the direction of half wave sinusoidal load movement. It can be seen from the figure 6 that the time history curves of point 3 and point 4 are very similar. However, it is quite different from the time history curve of point 1 and point 2 . When the vehicle starts to move from the starting position, point 3 and point 4, which are 5 meters away from the starting position, almost at the same time start to show small fluctuation. With the vehicle approaching, there are two Z-direction displacement peaks of the two points, and the first peak is slightly smaller than the second peak. Then it quickly turned to two downward peaks, and the first one was slightly larger than the second. According to table 2, points 3 and 4 have the largest Z-direction displacement when the load reaches the point at 0.336 seconds. The maximum value of point 3 is $1.358 \times 10-5 \mathrm{~m}$, and the maximum value of point 4 is $1.382 \times 10-5 \mathrm{~m}$.It can be seen that point 4 is far away from the load than point 3 , but its maximum $\mathrm{Z}$ displacement is larger than point 3. When the two points reach the maximum value in the upward direction, they quickly turn to the minimum value in the downward direction, and point 3 and point 4 reach the minimum $\mathrm{Z}$ direction displacement at 0.380 seconds. The minimum value of point 3 is $-1.495 \times 10-5 \mathrm{~m}$, and the minimum value of point 4 is $-1.537 \times 10-5 \mathrm{~m}$. Also the point $4 \mathrm{z}$-direction displacement minimum is smaller than that of point 3 .

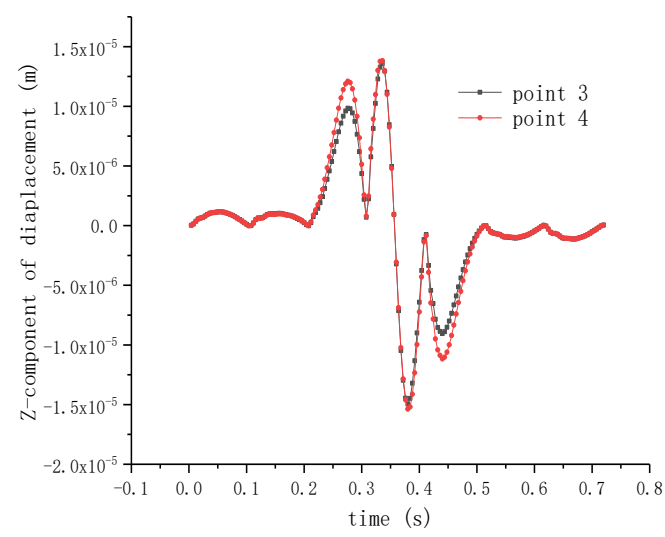

Fig.6. Point 3 and 4 time history curves

After the sharp changes of two up peaks and two down peaks, the displacements of point 3 and point 4 then quickly return to the zero vicinity and show small fluctuation as vehicle load continues to move forward. 
Fig. 7 is the z-direction displacement time history curve of point 2 and 4 in the direction of half wave sinusoidal load movement. Through comparison, it can be seen that point 2 only has an up and down displacement peak when the load arrives. Point 4, which is located at the bottom of the base course, shows a small fluctuation when the load is far away, but shows a positive first large peak when the load is near, and a second maximum peak when the load reaches. After that, it quickly turned to the maximum negative peak and the larger negative peak again. Then, as the load moves away, the point 4 displacement returns to the zero point, showing a negative micro amplitude fluctuation. Table 2 shows that the maximum positive peak and negative peak of point 4 are greater than the peak of point 2 .

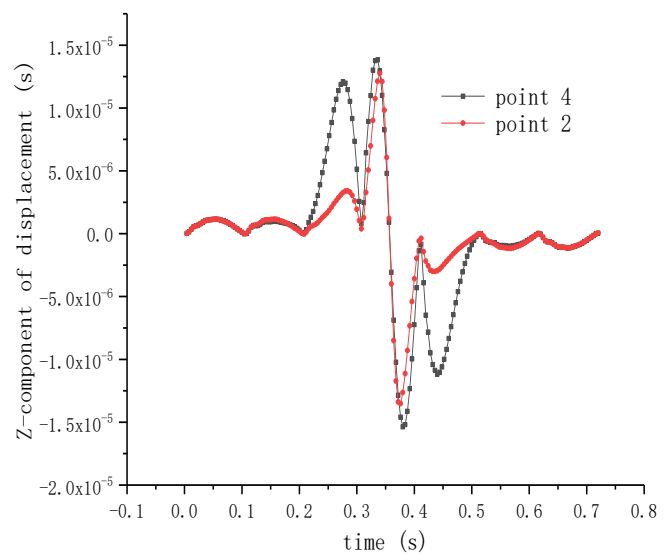

Fig.7. Point 2and 4 time history curves.

Table 2. maximum and minimum Z-direction displacement of 4 points under fluctuating load

\begin{tabular}{|c|c|c|c|c|}
\hline Point & $\begin{array}{c}\text { Maximum } \\
\mathbf{1 0} \text {-5/m }\end{array}$ & time/s & $\begin{array}{c}\text { Minimum } \\
\mathbf{1 0}^{-5} / \mathbf{m}\end{array}$ & time/s \\
\hline 1 & 1.231 & 0.376 & -1.166 & 0.340 \\
\hline 2 & 1.276 & 0.340 & -1.353 & 0.376 \\
\hline 3 & 1.358 & 0.336 & -1.495 & 0.380 \\
\hline 4 & 1.382 & 0.336 & -1.537 & 0.380 \\
\hline
\end{tabular}

It is found that no matter where the point is, the $\mathrm{z}$ direction displacement time history curve fluctuates frequently under the fluctuating load, which shows that the dynamic load has complex influence on the pavement structure. The peak direction of point 1 is first negative and then positive, and the peak fluctuation of points 2,3 and 4 is first positive and then negative, which shows that the peak fluctuation direction of the surface point is significantly different from that of the point under the surface. The peak time of Z-direction displacement is almost the same as that of load. However, due to the influence of point depth and load dynamic change, the Z-direction displacement peak value at different points is not the same. The deeper the point is, the larger the peak value is. It shows that the Z-direction displacement influence, the deeper down the road surface, the greater the influence.

\section{4 conclusions}

(1) no matter where the point is, the $z$-direction displacement time history curve fluctuates frequently under the fluctuating load, which shows that the dynamic load has complex influence on the pavement structure.

(2) The peak time of Z-direction displacement is almost the same as that of load. However, due to the influence of point depth and load dynamic change, the Zdirection displacement peak value at different points is not the same. The deeper the point is, the larger the peak value is.

(3) The influence of dynamic load on Z-direction displacement increases with the increase of depth.

\section{References}

1. JTG D50-2017.Specifications for design of highway asphalt pavement[S]. Beijing: People Traffic Press, (2017)

2. Huang X M. Roadbed and road surface engineering (the sixth edition) [M]. Beijing: People Traffic Publishing Company, (2019)

3. Zou J R, Zhang Z Q, Li T. Failure mechanism and control measures of common trunk highway semirigid base asphalt pavement[J]. Journal of Highway and Transportation Research and Development, 35(5), (2018)

4. Wei L Y, Yang Z L, Li S Q. Truck dynamic load on uneven pavement[J]. Journal of Chongqing Jiaotong University (natural science), 33(5), (2014)

5. Zhou Z F, Miao L W, Sun C. The mechanical response distribution of the typical asphalt concrete pavement structure[J]. Highway, (8), (2004).

6. Chen $\mathrm{H} \mathrm{X}$, Ma L, Song L F. Effect of the automobile driving state mechanical response of asphalt concrete pavement structure[J]. Highway, (3), (2015)

7. $\mathrm{Wu} \mathrm{J} \mathrm{T,} \mathrm{Ye} \mathrm{F.} \mathrm{Strain} \mathrm{behavior} \mathrm{of} \mathrm{asphalt} \mathrm{pavement}$ in accelerated pavement testing with MLS66 under heay-load and high-frequency[J]. China Journal of Highway and Transport, 27(10), (2014)

8. He B G. ANSYS Civil Engineering Application Example(the third edition)[M]. Beijing: China Water Power Press, (2011) 